УДК 616.89-008.441.13:615.099.036.8

Для цитирования: Селезнева И.А., Березовская М.А. Анализ причин летальности пациентов в наркологическом стационаpe с круглосуточным приемом больных. Сибирский вестник психиатрии и наркологии. 2018; 3 (100): 21-26. https://doi.org/10.26617/1810-3111-2018-3(100)-21-26

\title{
Анализ причин летальности пациентов в наркологическом стационаре с круглосуточным приемом больных
}

\author{
Селезнева И.А. ${ }^{1}$, Березовская М.А. ${ }^{2}$ \\ ${ }^{1}$ Красноярский краевой наркологический диспансер № 1 \\ Россия, 660048, Красноярск, ул. Комбайностроителей, д. 5 \\ ${ }^{2}$ Красноярский государственный медицинский университет им. профессора В.Ф. Войно-Ясенецкого \\ Россия, 660022, Красноярск, ул. Партизана Железняка, д. 1
}

\section{PEЗЮME}

Введение. Среди наркологических расстройств наибольшее распространение традиционно имеют расстройства, связанные с употреблением алкоголя, на их долю приходятся и самые значительные экономические и социальные потери. Цель. Изучение частоты, причин и индивидуальных особенностей летальных случаев при различных неотложных состояниях наркологического профиля, а также выявление наиболее частых коморбидных соматических заболеваний у пациентов КГБУЗ «ККНД № 1» в период с 2011 по 2016 г. Материалы и методы. Использовались официальные статистические отчеты КГБУЗ «ККНД № 1», истории болезни пациентов, умерших в ККНД № 1 в период с 2011 по 2016 г., протоколы патолого-анатомического исследования и судебно-медицинской экспертизы в количестве 91. Результаты. Представлен анализ летальных случаев больных в наркологическом стационаре с круглосуточным приемом пациентов на примере КГБУЗ «Красноярский краевой наркологический диспансер № 1» за 2011-2016 г. Уровень общей летальности среди пациентов составил $0,3 \%$, среди больных с алкогольными психозами $0,8 \%$. Описаны часто встречаемые соматические нарушения у пациентов с летальным исходом. Проанализированы факторы, приведшие к смерти пациентов в наркологическом стационаре при различных ургентных состояниях.

Ключевые слова: алкогольная зависимость, злоупотребление алкоголем, летальность, коморбидные соматические заболевания.

\section{ВВЕДЕНИЕ}

Злоупотребление алкоголем и алкогольная зависимость имеют широкую распространенность во всем мире. По данным ВО3, самая высокая распространенность алкогольной зависимости среди населения наблюдается в восточно-европейских странах, где она достигает уровня 16\%. В других западных европейских индустриальных странах уровень расстройств, связанных с употреблением алкоголя, находится в диапазоне между 7 и 10\%. В Европе ежегодно регистрируется 137000 летальных случаев в связи с алкоголизмом, из них 39000 на фоне цирроза печени, 13000 на фоне психических и неврологических расстройств. Кроме того, на фоне алкоголизма совершается 18000 суицидов и развивается 26000 онкологических заболеваний $[1,2,3]$. В России в последние десятилетия уровень наркологических расстройств также стабильно высок. Наибольшее распространение традиционно имеют расстройства, связанные с употреблением алкоголя, на их долю приходятся самые большие экономические и социальные потери $[4,5,6,7,8,9,10]$.

Большинство пациентов, страдающих наркологической патологией, наряду с основным наркологическим заболеванием имеют сопутствующие соматические болезни одной или нескольких систем внутренних органов. Часто соматические заболевания обостряются в состоянии абстиненции, но при этом характеризуются нетипичной клинической картиной со стертой симптоматикой $[11,12]$.

В различных регионах РФ специализированная помощь пациентам с психотическими расстройствам и коморбидной соматической патологией осуществляется в рамках различных моделей (психосоматические отделения общесоматической сети, отделения интенсивной терапии психиатрических и наркологических стационаров) [13, 14, 15]. По литературным данным, 5,7\% пациентов соматических стационаров составляют больные с наркологической патологией, при этом около половины из них - с расстройствами психотического уровня. В то же время в отделениях интенсивной терапии наркологических стационаров в первую очередь закономерно устанавливается диагноз наркологического расстройства, а соматические заболевания выступают в роли коморбидных. При различных подходах к диагностике и организации медицинской помощи пациентам с алкогольными психозами смертность колеблется от 0,5\% до 4\% [15].

Цель исследования: изучение частоты, причин и индивидуальных особенностей летальных случаев при различных неотложных состояниях наркологического профиля, а также выявление наиболее частых коморбидных соматических заболеваний среди пациентов КГБУЗ «ККНД № 1» в период с 2011 по 2016 г. 


\section{МАТЕРИАЛЫ И МЕТОДЫ}

В работе изучены официальные статистические отчеты КГБУЗ «ККНД № 1», истории болезни пациентов, умерших в ККНД № 1 в период с 2011 по 2016 г., протоколы патолого-анатомического исследования и судебно-медицинской экспертизы в количестве 91. Рассматривались следующие диагнозы: синдром отмены алкоголя, синдром отмены алкоголя, осложненный судорожными припадками, алкогольное психотическое расстройство, синдром отмены алкоголя с делирием, а также психотическое расстройство на фоне приема стимуляторов.

РЕЗУЛЬТАТЫ И ОБСУЖДЕНИЕ

Специализированная медицинская наркологическая помощь в КГБУЗ «ККНД № 1» круглосуточно оказывается пациентам - жителям Красноярска и Красноярского края. Пациенты поступают по направлению врачей-наркологов, а также доставляются бригадами скорой помощи и специализированными психиатрическими бригадами скорой помощи. Общее количество пациентов с алкогольными психозами за изученный период составило 4 810, большая часть из которых приходится на алкогольные делирии. Другие алкогольные психотические расстройства встречались реже. В связи с резким ростом количества пациентов с психотическими расстройствами на фоне приема наркотических веществ произошло соответствующее снижение количества пролеченных пациентов с алкогольной зависимостью (рис. 1).

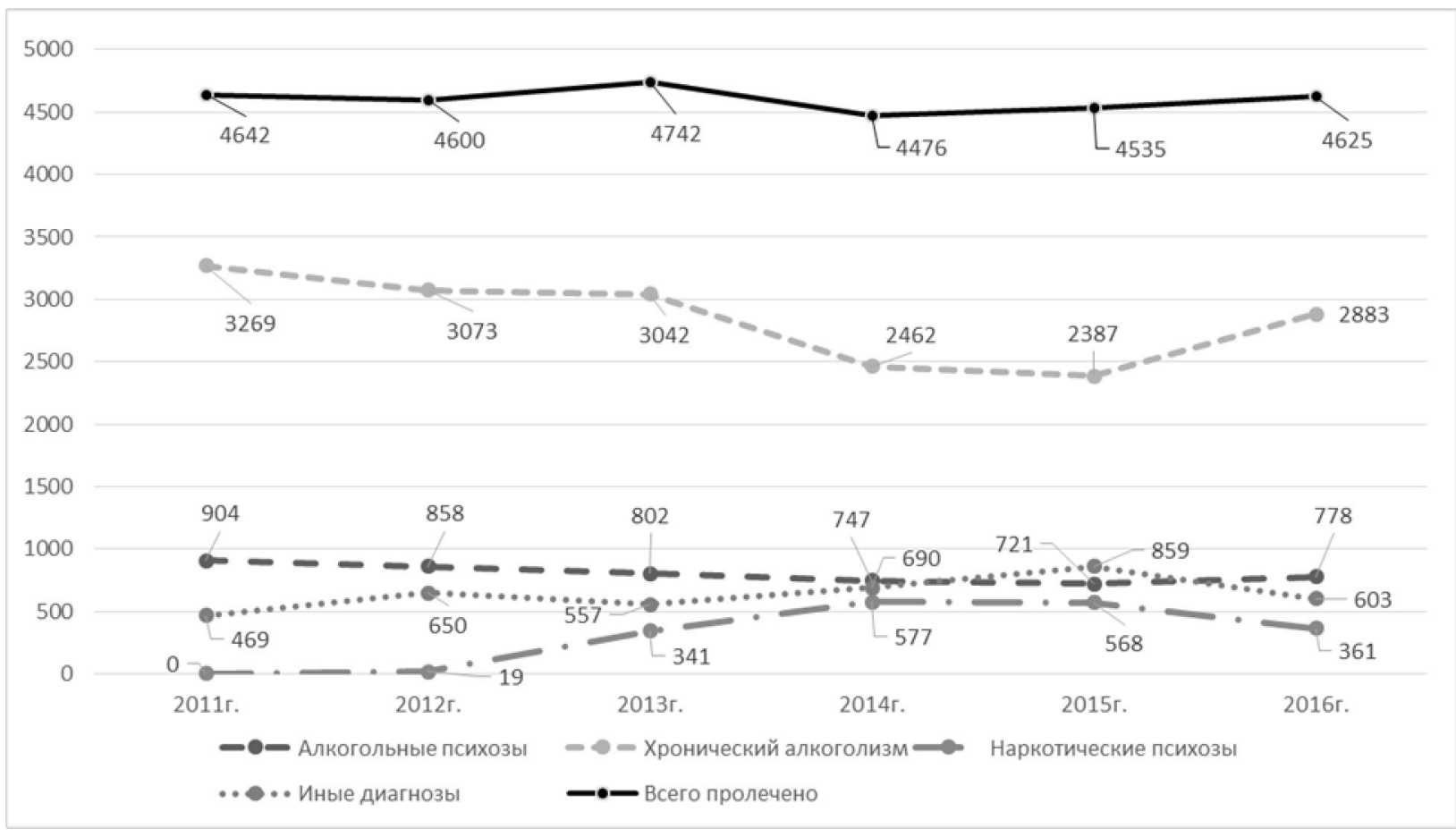

Р и с у н о к 1. Количество пролеченных больных с наркологической патологией в КГБУЗ «ККПНД № 1» за 2010-2016 гг.

В течение исследуемого периода значимых колебаний количества пациентов в КГБУЗ «ККНД № 1» не отмечено. В то же время произошли изменения в соотношении числа пролеченных больных с различными наркологическими нозологиями, а именно отмечено снижение количества пациентов, госпитализированных по поводу алкогольных психозов. Появилась значительная группа пациентов с психотическими нарушениями на фоне употребления психостимуляторов и синтетических каннабиноидов. В 2011 и 2012 гг. пациенты с психотическими нарушениями на фоне приема стимуляторов были единичны, в дальнейшем их количество резко возросло и стабилизировалось на показателе до 600 случаев в год, или $13 \%$ от всех пролеченных больных. Эти данные соответствуют аналогичным показателям в других регионах РФ [16].
За исследуемый период летальность пациентов в КГБУЗ «ККНД № 1» с круглосуточным приемом больных составила $0,3 \%$, летальность среди пациентов с алкогольными психозами $-0,8 \%$, среди пациентов с хроническим алкоголизмом $-0,3 \%$.

Проанализированные случаи летального исхода пациентов по диагнозам распределились следующим образом: синдром отмены алкоголя - 43 случая, алкогольный психоз - 41 случай, наркотический психоз - 7 случаев (табл. 1).

Наибольшее количество летальных исходов, зафиксированное среди пациентов наркологического профиля, приходится на случаи алкогольной зависимости, примерно в равных соотношениях встречаются психотические и непсихотические формы синдрома отмены алкоголя. 
Т а б л и ц а 1

Соотношение летальных исходов у пациентов с различными наркологическими диагнозами

\begin{tabular}{|l|c|c|c|c|c|c|}
\hline $\begin{array}{c}\text { Диагно3 по } \\
\text { МКБ-10 }\end{array}$ & 2011 г. & 2012 г. & 2013 г. & 2014 г. & 2015 г. & 2016 г. \\
\hline 10.30 & 5 & 2 & 2 & 5 & 2 & 5 \\
\hline 10.31 & 3 & 7 & 6 & 3 & 1 & 2 \\
\hline 10.40 & 7 & 2 & 0 & 5 & 3 & 6 \\
\hline 10.41 & 0 & 2 & 1 & 4 & 5 & 3 \\
\hline 10.52 & 0 & 1 & 1 & 1 & 0 & 0 \\
\hline 15.5 & 0 & 0 & 2 & 2 & 0 & 2 \\
\hline Всего & 15 & 14 & 12 & 20 & 12 & 18 \\
\hline
\end{tabular}

В группе пациентов с алкогольными психозами регистрировались массивные, затяжные алкогольные эксцессы, значительно чаще встречались ежедневные формы употребления алкоголя. Средний возраст пациентов оказался выше в группе лиц с алкогольными психозами и значительно ниже у пациентов с психозами на фоне употребления стимуляторов. В последней группе пациентов обнаружены высокие показатели досуточной летальности и, как следствие, высокая частота расхождения клинического и патолого-анатомического диагнозов (табл. 2).

Т а б л и ц а 2

Основные статистические показатели случаев с летальным исходом пациентов КГБУЗ «Красноярский краевой наркологический диспансер №1»

\begin{tabular}{|l|c|c|c|}
\hline \multicolumn{1}{|c|}{ Показатель } & \multicolumn{3}{|c|}{ Нозологическая группа } \\
\cline { 2 - 4 } & $\begin{array}{c}\text { Синдром } \\
\text { отмены } \\
\text { алкоголя }\end{array}$ & $\begin{array}{c}\text { Алкогольные } \\
\text { психозы }\end{array}$ & $\begin{array}{c}\text { Употребле- } \\
\text { ние стиму- } \\
\text { ляторов }\end{array}$ \\
\hline Число больных (n=91) & 43 & 41 & 7 \\
\hline $\begin{array}{l}\text { Соотношение мужчин и } \\
\text { женщин }\end{array}$ & $4 / 10$ & $28 / 7$ & $3 / 4$ \\
\hline Средний возраст & 47,5 & 51,2 & 31,6 \\
\hline $\begin{array}{l}\text { Продолжительность упо- } \\
\text { требления ПАВ }\end{array}$ & 14,5 дня & $\begin{array}{c}\text { н,5 (постоян- } \\
\text { ные формы } \\
\text { пьянства) }\end{array}$ & 7,5 дня \\
\hline Летальность & $0,3 \%$ & $0,8 \%$ & $0,3 \%$ \\
\hline $\begin{array}{l}\text { Средняя длительность пре- } \\
\text { бывания в стационаре }\end{array}$ & 3,2 суток & 5,0 суток & 2,5 суток \\
\hline Досуточная летальность & $49 \%$ & $9,5 \%$ & $70 \%$ \\
\hline
\end{tabular}

Тела пациентов, умерших в КГБУЗ «ККНД № 1», направлялись на вскрытие в патолого-анатомическое бюро и бюро судебно-медицинской экспертизы. По результатам выданных заключений у $100 \%$ умерших пациентов при вскрытии были обнаружены изменения внутренних органов, как правило, двух и более систем (табл. 3).

При алкогольном абстинентном синдроме явления алкогольной кардиомиопатии (АКМП) выявлены в $21 \%$ случаев, в $14 \%$ случаев имели место признаки атеросклероза аорты и кровеносных сосудов. Количество случаев с острой коронарной недостаточностью (ОКН) и инфарктом миокарда (ОИМ) было выше у пациентов, поступивших в стационар по поводу синдрома отмены алкоголя. Количество больных с артериальной гипертонией (АГ), наоборот, было выше в группе пациентов с алкогольными психозами.
Т а б ли ц а 3 Патолого-анатомические изменения внутренних органов у больных, умерших в КГБУЗ «ККПНД № 1» в 2011-2016 гг.

\begin{tabular}{|c|c|c|c|c|c|c|}
\hline \multirow[t]{2}{*}{$\begin{array}{c}\text { Патологическое } \\
\text { изменение }\end{array}$} & \multicolumn{2}{|c|}{$\begin{array}{c}\text { Алкоголь- } \\
\text { ный абсти- } \\
\text { нентный } \\
\text { синдром }\end{array}$} & \multicolumn{2}{|c|}{$\begin{array}{c}\text { Алкоголь- } \\
\text { ные психо- } \\
\text { зы }\end{array}$} & \multicolumn{2}{|c|}{$\begin{array}{c}\text { Психозы } \\
\text { стимулято- } \\
\text { ры }\end{array}$} \\
\hline & \begin{tabular}{c|} 
Aбc. \\
$\mathrm{N}=43$
\end{tabular} & $\%$ & $\begin{array}{l}\text { Aбс. } \\
\mathrm{N}=41\end{array}$ & $\%$ & $\begin{array}{l}\text { Aбc. } \\
\mathrm{N}=7\end{array}$ & $\%$ \\
\hline $\begin{array}{l}\text { Алкогольная } \\
\text { кардиомиопатия }\end{array}$ & 9 & 21 & 10 & 24,4 & - & - \\
\hline ОКН, ОИМ & 6 & 14 & 2 & 4,9 & - & - \\
\hline Артериальная гипертензия & 3 & 7 & 12 & 30 & - & - \\
\hline $\begin{array}{l}\text { Атеросклероз аорты, сосу- } \\
\text { дов }\end{array}$ & 6 & 14 & 9 & 22 & 1 & 14 \\
\hline ТЭЛА & 1 & 2,3 & 2 & 4,9 & - & - \\
\hline Разрыв & 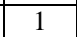 & 2,3 & - & 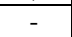 & - & 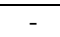 \\
\hline Пневмония & 8 & 19 & 20 & 48,8 & 2 & 28,6 \\
\hline Плеврит & 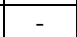 & - & 2 & 4,9 & 1 & 14 \\
\hline Туберкул & 1 & 2,3 & 1 & 2,4 & - & - \\
\hline Гепатоз & 18 & 42 & 24 & 56 & - & - \\
\hline Гепатит & 6 & 14 & 4 & 9,8 & 3 & 43 \\
\hline Цирроз п & 1 & 2,3 & 5 & 12,2 & - & -1 \\
\hline Панкреатит, панкре & 13 & 30,2 & 19 & 46,3 & - & - \\
\hline Нефропатия, нефронекроз & 10 & 23,2 & 7 & 17 & 2 & 28 \\
\hline Миокардит & - & - & - & - & 3 & 43 \\
\hline Менингит & 2 & 4,7 & 1 & 3,1 & 1 & 14 \\
\hline Сепсис & 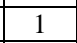 & 2,3 & - & - & - & - \\
\hline $\begin{array}{l}\text { Дистрофическ } \\
\text { внутренних ор } \\
\end{array}$ & 3 & 7 & 25 & 61 & 3 & 43 \\
\hline Отек мозга & 26 & 60,5 & 32 & 78 & 3 & 43 \\
\hline Отек легких & 17 & 40 & 22 & 54 & 2 & 28 \\
\hline ВИЧ & 3 & 7 & 1 & 2,4 & 3 & 43 \\
\hline $\begin{array}{l}\text { Онкологические заболева- } \\
\text { ния }\end{array}$ & - & - & 4,9 & & - & - \\
\hline
\end{tabular}

Несомненно, одним из факторов, ухудшающих прогноз пациентов с алкогольным делирием, является гипоксия тканей, прежде всего сердца и головного мозга. Поэтому наиболее полная коррекция нарушений сердечно-сосудистых расстройств и расстройств дыхательной системы становится приоритетной задачей для врача, оказывающего неотложную медицинскую помощь [17]. Таким образом, у пациентов с ургентными наркологическими состояниями высока распространенность заболеваний сердечно-сосудистой системы, с нарушением системы микроциркуляции крови, приводящим к гипоксическим поражениям внутренних органов [18].

Заболевания легких выявлялись при патологоанатомическом исследовании в $19 \%$ случаев при алкогольной абстиненции и в $47 \%$ случаях при алкогольных психозах. Тяжелые, преимущественно внебольничные пневмонии у пациентов с алкогольными психозами всегда описываются в литературе как признаки неблагоприятного прогноза. Часто пневмонии и специфический воспалительный процесс в легких становятся конкурирующими заболеваниями в заключениях патолого-анатомического вскрытия. Туберкулез легких встречался в анализируемом временном периоде только в двух случаях, несмотря на высокую частоту сочетания этих двух социально обусловленных и значимых заболеваний $[19,20,21]$. 
У подавляющего большинства пациентов диагностированы сочетанные заболевания желудочнокишечного тракта. Кроме того, более чем в 60\% случаев при алкогольных психозах выявлялись дистрофические изменения внутренних органов. У большинства пациентов независимо от диагноза при поступлении при патолого-анатомическом вскрытии описываются дегенеративные изменения нейронов головного мозга.

Пациенты, поступившие с клиникой психозов на фоне употребления стимуляторов, отличались преобладанием септических состояний, наличием тяжелых пневмоний, нередко абсцедирующих, менингитов, при этом в приемном покое у них нередко отмечалось выраженное психомоторное возбуждение. Диагностировать соматическое заболевание при выраженном психомоторном возбуждении и наличии наркологического анамнеза - непростая задача для врачей психиатров-наркологов. В дальнейшем течение септических осложнений у таких пациентов бывало молниеносным, а психомоторное возбуждение сменялось нарушением сознания.

Обращает на себя внимание значительное количество малообследованных пациентов, которые находились в стационаре менее суток. Таких пациентов с алкогольными психозами было 19,5\%, с синдромом отмены алкоголя - 49\%, а среди больных с наркотическими психозами - 70\%. Это группа ургентных больных, требующих неотложной медицинской помощи и большого объема инструментальных методов обследования. Объективные сложности при установлении сопутствующего диагноза, определении причины тяжести состояния, а также нетипичные формы течения соматических заболеваний на фоне абстинентных расстройств приводят к высокой досуточной летальности пациентов. Часто встречаются случаи расхождения диагнозов клинициста и патологоанатома при досуточной летальности. Причинами расхождения являются объективные трудности обследования пациента, недостаточное количество времени для установления диагноза в связи с крайне поздним обращением пациентов за медицинской помощью, несмотря на ухудшающееся самочувствие, употребление психоактивных веществ, низкий социальный статус и стигматизация пациентов в общесоматической сети $[22,23,24]$.

\section{ЗАКЛЮЧЕНИЕ}

Таким образом, на территории Красноярска отмечено снижение количества больных, пролеченных с заболеваниями, связанными с употреблением алкоголя, резкий рост с последующей стабилизацией числа пациентов, употребляющих стимуляторы и синтетические каннабиноиды. Такие больные госпитализируются с психотическими расстройствами и выраженными аффективными проявлениями, что препятствует выявлению тяжелых сопутствующих соматических состояний.

Среди пациентов, госпитализированных по поводу алкогольных психозов, закономерно выше уро- вень летальности по сравнению с категорией больных с синдромом отмены алкоголя. Наступление смерти у больных с ургентными наркологическими состояниями наиболее часто связано с развитием острой коронарной недостаточности при синдроме отмены алкоголя и развитием пневмоний у больных с алкогольными делириями. Широкий спектр соматических нарушений у пациентов с тяжелыми состояниями, угрожающими жизни, требует комплексного подхода к лечению и обследованию, обширных клинических знаний от врачей психиатровнаркологов, а также обсуждения вопроса о формах и моделях оказания неотложной наркологической помощи.

\section{КОНФЛИКТ ИНТЕРЕСОВ}

Авторы заявляют об отсутствии конфликта интересов в связи с публикацией данной статьи.

\section{ИСТОЧНИК ФИНАНСИРОВАНИЯ}

Авторы заявляют об отсутствии финансирования при проведении исследования.

\section{СООТВЕТСТВИЕ ПРИНЦИПАМ ЭТИКИ}

Работа соответствует этическим стандартам Хельсинской декларации ВМА (протокол заседания этического комитета ГБОУ ВПО «Красноярский государственный медицинский университет имени проф. В.Ф. Войно-Ясенецкого» Минздрава России № 68/2016 от 2 марта 2016 г.).

\section{ЛИТЕРАТУРА}

1. Mann K., Hoch E., Batra A., Bonnet U., Günthner A., Reymann G., Soyka M., Wodarz N., Schäfer M. Leitlinien orientierte Behandlung alkoholbezogener Störungen. Nervenarzt. 2016; 1: $13-25$.

2. Soyka M. Psychotische Störungen durch Alkohol - eine eigene diagnostische Entität? Nervenarzt. 2014; 9: 1093-1098.

3. World Health Organization Global status report on alcohol and health. Geneva: WHO Press, 2011.

4. Алексеевская Т.И., Селедцов А.А. Оценка экономического ущерба от алкогольассоциированной смертности среди трудоспособного женского населения Иркутской области. Вопросы наркологии. 2015; 4: 61-72.

5. Бохан Н.А., Мандель А.И., Максименко Н.Н., Михалева Л.Д. Смертельные исходы при алкогольной зависимости. Наркология. 2007; 12: 37-40.

6. Бурцев А. А., Кошкина Е. А. Об актуальности проблематики автодорожного травматизма, связанного с управлением транспортными средствами в состоянии опьянения в России. Вопросы наркологии. 2015; 1: 105-116.

7. Кошкина Е.А. Заболеваемость психическими и поведенческими расстройствами, связанными с употреблением психоактивных веществ в Российской Федерации в динамике за 5 лет. Вопросы наркологии. 2011; 1: 17-27.

8. Немцов А.В., Изаровский Б.В., Сахаров А.В. Годичный тренд алкогольных отравлений и психозов. Наркология. 2014; $1: 25-29$.

9. Немцов А.В., Орлов А.В., Шеин В.В. Соматические заболевания и травмы у больных «пивным» и «водочным» алкоголизмом. Вопросы наркологии. 2014; 3: 56-63.

10. Бохан Н.А., Мандель А.И., Кузнецов В.Н. Алкогольная смертность в отдалённых сельских районах Западной Сибири. Наркология. 2011; 10, 9 (117): 43-47.

11. Бохан Н.А., Семке В.Я. Коморбидность в наркологии. Томск: Изд-во Том. ун-та, 2009: 510.

12. Shin SS., Mathew TA., Yanova GV., Fitzmaurice GM., Livchits V., Yanov SA., Strelis AK., Mishustin SP., Bokhan NA., Lastimoso CS., Connery HS., Hart JE., Greenfield SF. Alcohol Consumption among men and women with tuberculosis in Tomsk, Russia. Central European Journal of Public Health. 2010 Sep; 18 (3): 132-8. 
13. Бохан Н.А., Коробицина Т.В. Ассоциированные формы алкоголизма в общесоматической амбулаторной сети. Томск, 2000: 232.

14. Менделевич В.Д. Терапия наркологических расстройств в общемедицинской сети: смена парадигмы. Вопросы наркологии. 2014; 2: 141-153.

15. Прокудин В.Н., Музыченко А.П., Хунданов Л.Л. Наркологические расстройства у больных многопрофильной соматической больницы. Наркология. 2002; 6: 40-43.

16. Кошкина Е.А., Вышинский К.В., Павловская Н.И. и др. Особенности употребления психоактивных веществ среди населения отдельных регионов России. Наркология. 2010; 4: 16-24.

17. Сахаров А.В., Говорин Н.В., Болванов А.И. Состояние микроциркуляции крови у больных алкоголизмом с неосложненным синдромом отмены алкоголя. Вопросы наркологии. 2014; 4: 64-69.

18. Бохан Н.А., Иванова С.А., Мандель А.И., Жернова Е.В., Кисель Н.И. Когнитивные функции и процессы апоптоза у больных алкоголизмом: эффекты нейрометаболической коррекции. Наркология. 2012; 7: 51-55.
19. Лещенко И.В., Бобылева З.Д., Трифанова Н.М. Внебольничная пневмония: от национальных рекомендаций к региональным стандартам. Клиническая медииина. 2014; 6: 35-40.

20. Эмиралиева 3.А. Структура смертности больных туберкулезом в течение первого года наблюдения. Бюллетень меди цинских интернет-конференций. 2013; 3 (3): 501-503.

21. Kyle I. The Epidemiology of Alcohol Abuse and Pneumonia. Alcohol Use Disorders and the Lung. 2013; 14: 19-34.

22. Лелевич С.В. Состояние нейромедиаторных систем головного мозга и метаболизма глюкозы в печени и скелетной мускулатуре крыс при алкогольной абстиненции. Bonросы наркологии. 2013; 4: 19-28.

23. Бохан Н.А., Иванов А.А., Мандель А.И. Региональная динамика и исходы заболеваемости алкогольными психозами. Наркология. 2012; 8: 38-43.

24. Naimi T.S., Xuan Z., Brown D.W. et al. Confounding and studies of «moderate» alcohol consumption: the case of drinking frequency and implications for low-risk drinking guidelines. Addiction. 2012; 108: 1534-1543.

Поступила в редакцию 30.04 .2018 Утверждена к печати 25.06.2018

Селезнева Ирина Андреевна, врач психиатр-нарколог, заведующая отделением неотложной наркологической помощи.

Березовская Марина Альбертовна, д.м.н., доцент, заведующая кафедрой психиатрии и наркологии с курсом последипломного образования.

Селезнева Ирина Андреевна, 9080120784@mail.ru

For citation: Selezneva I.A., Berezovskaya M.A. Analysis of factors of patient mortality in twenty-four-hour narcological dispensary. Siberian Herald of Psychiatry and Addiction Psychiatry. 2018; 3 (100): 21-26. https://doi.org/10.26617/1810-3111-2018$3(100)-21-26$

\section{Analysis of factors of patient mortality in twenty-four-hour narcological dispensary Selezneva I.A. ${ }^{1}$ Berezovskaya M.A. ${ }^{2}$}

${ }^{1}$ Krasnoyarsk Regional Narcological Dispensary no. 1 Kombainostroiteley Street 5, 660048, Krasnoyarsk, Russian Federation

${ }^{2}$ Krasnoyarsk State Medical University named after Professor V.F. Voyno-Yasenetsky

Partizan Zheleznyak Street, 1, 660022, Krasnoyarsk, Russian Federation

\section{ABSTRACT}

Objective: to study causes of mortality in the narcological dispensary of patients with urgent narcological pathology, character of co-morbid somatic pathology, to study frequency, causes, individual features of lethal ends and reveal frequent co-morbid somatic pathology in patients of Krasnoyarsk Regional Narcological Dispensary no. 1 for the period from 2010 to 2016. Materials and Methods. Official statistical reports of Krasnoyarsk Regional Narcological Dispensary no. 1, medical files of patients deceased in Krasnoyarsk Regional Narcological Dispensary no. 1 for the period from 2010 to 2016; pathoanatomic protocols and forensic-medical examination in number 91 were studied. The method of statistical-mathematical analysis was used. Results. This paper presents an analysis of factors of patient mortality in twenty-four-hour narcological dispensary, using the example of the Krasnoyarsk Regional Narcological Dispensary no. 1 for the period from 2010 to 2016. Total mortality rate among patients was $0.3 \%$ and $0.8 \%$ among patients with alcoholic psychosis. Frequent somatic disorders were described in patients with a lethal end. Mortality factors directly leading to death from alcoholic psychosis and alcohol withdrawal syndrome were analyzed.

\section{Keywords: alcohol dependence, alcohol abuse, mortality, comorbid somatic diseases.}

\section{REFERENCES}

1. Mann K., Hoch E., Batra A., Bonnet U., Günthner A., Reymann G., Soyka M., Wodarz N., Schäfer M. Leitlinien orientierte Behandlung alkoholbezogener Störungen. Nervenarzt. 2016; 1: 13-25.

2. Soyka M. Psychotische Störungen durch Alkohol - eine eigene diagnostische Entität? Nervenarzt. 2014; 9: 1093-1098.

3. World Health Organization Global status report on alcohol and health. Geneva: WHO Press, 2011.

4. Alekseevskaya T.I., Seledtsov A.A. Ocenka jekonomicheskogo ushherba ot alkogol'-associirovannoj smertnosti sredi trudosposobnogo zhenskogo naselenija Irkutskoj oblasti [Evalua- tion of economic damage alcohol-associated mortality between employee women population in Irkutsk area]. Voprosy narkologii - Journal of Addiction Problems. 2015; 4: 61-72 (in Russian).

5. Bokhan N.A., Mandel A.I., Maksimenko N.N., Mikhaleva L.D. Smertel'nye ishody pri alkogol'noj zavisimosti [Results of alcohol abuse]. Narkologija - Narcology. 2007; 12: 37-40 (in Russian).

6. Burtsev A.A., Koshkina E.A. Ob aktual'nosti problematiki avtodorozhnogo travmatizma, svjazannogo s upravleniem transportnymi sredstvami v sostojanii op'janenija v Rossi [Actuality issues of road injures related to drunk driving in Russian 
Federation]. Voprosy narkologii - Journal of Addiction Problems. 2015; 1: 105-116 (in Russian).

7. Koshkina E.A. Zabolevaemost' psihicheskimi i povedencheskimi rasstrojstvami, svjazannymi s upotrebleniem psihoaktivnyh veshhestv v Rossijskoj Federacii v dinamike za 5 let [Morbidity of mental diseases related to substance use in Russian Federation in 5-years dynamic]. Voprosy narkologii - Journal of Addiction Problems. 2011; 1: 17-27 (in Russian).

8. Nemtsov A.V., Izarovsky B.V., Sakharov A.V. Godichnyj trend alkogol'nyh otravlenij i psihozov [Year trend of alcohol psychosis and alcohol intoxication]. Narkologija - Narcology. 2014; 1: 25-29 (in Russian).

9. Nemtsov A.V., Orlov A.V., Shein V.V. Somaticheskie zabolevanija i travm u bol'nyh «pivnym» i «vodochnym» alkogolizmom [Somatic diseases and injures of patients with «beer» alcoholism» and «vodka» alcoholism]. Voprosy narkologii - Journal of Addiction Problems. 2014; 3: 56-63 (in Russian).

10. Bokhan N.A., Mandel A.I., Kuznetsov V.N. [Alcohol mortality in remote rural districts of West Siberia]. Narkologiya - Narcology. 2011; 10, 9 (117): 43-47. (in Russian).

11. Bokhan N.A., Semke V.Ya. Komorbidnost' v narkologii [Comorbidity in Addiction Psychiatry]. Tomsk: Publishing House of Tomsk University, 2009: 510 (in Russian).

12. Shin SS., Mathew TA., Yanova GV., Fitzmaurice GM., Livchits V., Yanov SA., Strelis AK., Mishustin SP., Bokhan NA., Lastimoso CS., Connery HS., Hart JE., Greenfield SF. Alcohol Consumption among men and women with tuberculosis in Tomsk, Russia. Central European Journal of Public Health. 2010 Sep; 18 (3): $132-8$.

13. Bokhan N.A., Korobitsina T.V. Associirovannye formy alkogolizma v obshhesomaticheskoj ambulatornoj seti [Associated forms of alcoholism in general somatic network dispensary]. Tomsk, 2000: 232 (in Russian).

14. Mendelevich V.D. Terapija narkologicheskih rasstrojstv v obshemedicinskoj seti: smena paradigmy [Therapy of narcological diseases in general medical network: paradigm changes]. Voprosy narkologii - Journal of Addiction Problems. 2014; 2: $141-153$ (in Russian).

15. Prokudin V.N., Muzychenko A.P., Hundanov L.L. Narkologicheskie rasstrojstva u bol'nyh mnogoprofil'noj somaticheskoj bol'nicy [Narcological diseases of patients in multidisciplinary somatic dispensary]. Narkologija - Narcology. 2002; 6: 40-43 (in Russian).

16. Koshkina E.A., Vyshinsky K.V., Pavlovskaya N.I. i dr. Osobennosti upotreblenija psihoaktivnyh veshhestv sredi naselenija otdel'nyh regionov Rossii [Features of substance use among population of separate areas of Russian Federation]. Narkologija - Narcology. 2010; 4: 16-24 (in Russian).

17. Sakharov A.V., Govorin N.V., Bolvanov A.I. Sostojanie mikrocirkuljacii krovi u bol'nyh alkogolizmom s neoslozhnennym sindromom otmeny alkogolja [Condition of blood microcirculation of patients with alcohol withdrawal syndrome]. Voprosy narkologii - Journal of Addiction Problems. 2014; 4: 64-69 (in Russian).

18. Bokhan N.A., Ivanova S.A., Mandel A.I., Zhernova E.V., Kisel N.I. Kognitivnye funkcii i processy apoptoza u bol'nyh alkogolizmom: jeffekty nejrometabolicheskoj korrekcii [Cognitive functions and apoptosis processes of alcohol abusers: neurometabolic correction effects]. Narkologija - Narcology. 2012; 7: 51-55 (in Russian).

19. Leshchenko I.V., Bobyleva Z.D., Trifanova N.M. Vnebol'nichnaja pnevmonija: ot nacional'nyh rekomendacij k regional'nym standartam [Community-acquired pneumonia: from national recommendations to regional standards]. Klinicheskaja medicina - Clinical Medicine. 2014; 6: 35-40 (in Russian).

20. Yemiralieva Z.A. Struktura smertnosti bol'nyh tuberkulezom v techenie pervogo goda nabljudenija [Structure of mortality of patients with tuberculosis in first year observation]. Bjulleten' medicinskih internet-konferencij - Bulletin of Medical Internet Conferences. 2013; 3 (3): 501-503 (in Russian).

21. Kyle I. The Epidemiology of Alcohol Abuse and Pneumonia. Alcohol Use Disorders and the Lung. 2013; 14: 19-34.

22. Lelevich S.V. Sostojanie nejromediatornyh sistem golovnogo mozga i metabolizma gljukozy v pecheni i skeletnoj muskulature krys pri alkogol'noj abstinencii [Condition of neuro-mediator system of brain and methabolism of glucosae in liver and skeleton muscles of rats with alcohol withdrawal syndrome]. Voprosy narkologii - Journal of Addiction Problems. 2013; 4: 19-28 (in Russian).

23. Bokhan N.A., Ivanov A.A., Mandel A.I. Regional'naja dinamika i ishody zabolevaemosti alkogol'nymi psihozami [Regional dynamic and outcomes of sickness rate with alcohol psychoses]. Narkologiva - Narcology. 2012; 11, 8 (128): 38-43 (in Russian)

24. Naimi T.S., Xuan Z., Brown D.W. et al. Confounding and studies of «moderate» alcohol consumption: the case of drinking frequency and implications for low-risk drinking guidelines. Addiction. 2012; 108: 1534-1543.

Received April 30.2017 Accepted June 25.2018

Selezneva Irina A., addiction specialist, Head of the Unit of Narcological Emergency, Krasnoyarsk Regional Narcological Dispensary no. 1, Krasnoyarsk, Russian Federation.

Berezovskaya Marina A., MD, associate professor, Head of Department of Psychiatry and Narcology with the course of postgraduate education, Krasnoyarsk State Medical University named after Professor V.F. Voyno-Yasenetsky, Krasnoyarsk, Russian Federation.

Selezneva Irina A., 9080120784@mail.ru 